\title{
Control of type 2 diabetes mellitus among general practitioners in private practice in nine countries of Latin America
}

\author{
Gloria Lopez Stewart, ${ }^{1}$ Marcos Tambascia, ${ }^{2}$ Juan Rosas Guzmán, ${ }^{3}$ \\ Federico Etchegoyen, ${ }^{4}$ Jorge Ortega Carrión, ${ }^{5}$ and Sofia Artemenko ${ }^{6}$
}

Suggested citation Lopez Stewart G, Tambascia M, Rosas Guzmán J, Etchegoyen F, Ortega Carrión J, Artemenko S. Control of type 2 diabetes mellitus among general practitioners in nine countries of Latin America. Rev Panam Salud Publica. 2007;22(1):12-20.

ABSTRACT Objectives. To better understand how diabetes care and control are being administered by general practitioners/nonspecialists in private practice in nine countries of Latin America, and to identify the most significant patient-and physician-related barriers to care.

Methods. A multicenter, cross-sectional, epidemiological survey was conducted in nine countries in Latin America: Argentina, Brazil, Chile, Costa Rica, Ecuador, Guatemala, Mexico, Peru, and Venezuela. General practitioners in private practice were asked to provide care and control data for patients 18 to 75 years of age with type 2 diabetes mellitus (T2DM), including demographics, medical and medication history, laboratory exams, and information on the challenges of patient management.

Results. Of the 3592 patient questionnaires returned by 377 physicians, $60 \%$ of the patients had a family history of diabetes, 58\% followed a poor diet, $71 \%$ were sedentary, and $79 \%$ were obese or overweight. Poor glycemic control (fasting blood glucose $\geq 110 \mathrm{mg} / \mathrm{dL}$ ) was observed in $78 \%$ of patients. The number of patients with $\mathrm{HbA1c}<7.0 \%$ was $43.2 \%$. Glycemic control decreased significantly with increased duration of T2DM. Comorbid conditions associated with T2DM were observed in $86 \%$ of patients; insulin use and comorbid conditions, especially those associated with microvascular complications, increased significantly disease $d u-$ ration. Ensuring compliance with recommended diet and exercise plans was the most-cited patient management challenge.

Conclusions. Blood glucose levels are undercontrolled in T2DM patients in the private health care system in Latin America, particularly among those who have had the disease the longest ( $>15$ years). Considering the differences between private and public health care in Latin America, especially regarding the quality of care and access to medication, further studies are called for in the public setting. Overall, a more efficient and intensive program of T2DM control is required, including effective patient education programs, adjusted to the realities of Latin America.

Key words Diabetes mellitus, type 2; diabetes complications; health services accessibility; patient compliance; Latin America.

\footnotetext{
Latin American Diabetes Association and Universidad de Chile, División Occidente, Santiago, Chile. Send correspondence to: Gloria Lopez Stewart, Universidad de Chile, Hannover 5754, La Reina, Santiago, Chile; tel: 56-2-226-8075; fax: 56-2 226 8075; e-mail: glopezstewart@mi.cl.
}

2 University of Campinas and the Brazilian Society of Diabetes, Campinas, São Paulo, Brazil.

Latin American Diabetes Association and Guanajuato University, Mexico.

4 Hospital Universitario Austral and Sanatorio Materdei, Buenos Aires, Argentina.
5 Clinica de la FAE Quito, Quito, Ecuador.

6 GlaxoSmithKline Inc., Research Triangle Park, North Carolina, United States of America. 
Type 2 diabetes mellitus (T2DM) is a leading cause of death and disability in both developed and developing countries. A study conducted in 2000 projects that the worldwide T2DM estimated prevalence of $2.8 \%$ will rise to $4.4 \%$ by 2030 (1). Diabetes is more common in certain ethnic groups, namely Blacks (2) and Hispanics (3); therefore, many countries in Latin America show a high or rising prevalence of T2DM $(4,5)$. Despite evidencebased clinical recommendations and guidelines for the Region of the Americas on diabetes care, significant delivery barriers have been identified by studies in Brazil (6), Chile (7), Jamaica (8), and Mexico (9). The gap between health spending and the cost of diabetes care in the Region was noted by Barceló et al. (10), who suggests that poor disease control has led to a high frequency of complications, disabilities, and premature mortality. Gagliardino et al. (11), in studying the impact of educational programs on the quality of diabetes care in Latin America, observed that systematic checking of metabolic control was inadequate in up to $72 \%$ of cases.

Diabetes treatment and management strategies are constantly evolving, but in Latin America there is a lack of well-controlled epidemiologic information on diabetes to evaluate the impact of improvements on disease management. This study, "Diabetes En America Latina" (DEAL), was designed to evaluate the quality of T2DM care provided by general practitioners in private practice in Latin America. It also aims to ascertain how successful the prescribed treatments are in controlling the disease and what the obstacles to care might be.

\section{METHODS}

The DEAL study was a multicenter, cross-sectional, epidemiological, questionnaire-based study carried out over the course of a year beginning in October 2004 and taking place in nine Latin American countries: Argentina, Brazil, Chile, Costa Rica, Ecuador, Guatemala, Mexico, Peru, and Vene- zuela. These countries were selected for their population size, as well as the availability of some level of structured information on the health care system and T2DM prevalence or incidence. The target sample size for the study was 560 general practitioners (GPs) in private practice, each contributing 10 patient questionnaires. GPs invited to participate were required to meet the following three criteria: (1) a minimum of two years experience, beyond residency; (2) a full-time, active clinical practice, defined as three or more days per week and treating at least 100 patients per week; and (3) at least five T2DM patients per month. Of those invited, $32.7 \%$ either did not meet the criteria, were unreachable, declined to participate, dropped out of the study, or failed to return study material.

Patients eligible for the study were males and females between 18 and 75 years of age who been diagnosed with T2DM as defined by the American Diabetes Association (12) (also accepted in Latin America); were receiving an oral hypoglycemic agent (OHA) or insulin; and had given written, informed consent, where required.

Following receipt of the study questionnaires, GPs were allowed two weeks to review patient charts and complete questionnaires for the first 8-12 consecutive T2DM patients to visit the clinic. Questionnaire responses were handwritten, and collected information on general health, including weight and height; demographic data (age and gender, age at the diagnosis, mean duration of the disease, type of drug insurance coverage); lifestyle; test results; medication history; hospitalizations; comorbidities; follow-up compliance; and consultations with specialists.

Glycosylated hemoglobin (HbA1c) levels at the time of diagnosis and during the three months preceding the study were evaluated. If the $\mathrm{HbA} 1 \mathrm{c}$ readings were not available for this time period and the testing was deemed necessary by the evaluating GP, the sponsor covered the cost of testing when the patient's health insurance (either public or private) would not.
Note that currently, $\mathrm{HbA} 1 \mathrm{c}$ determination is the preferred, or "gold standard," for evaluating T2DM control. Fasting plasma glucose (FPG) is highly variable, does not represent a good measure of control over time, and is best used when an "instant picture" of the last few hours of control is needed. The HbA1c control criteria are aligned with the current guidelines for T2DM care in Latin America (Latin America Consensus on Diabetes Mellitus and Hypertension, 2004) (13). Moreover, some countries, such as Brazil, define the minimum requirements for control, treatment, and therapeutic algorithms, according to $\mathrm{HbA} 1 \mathrm{c}$ and plasma glucose levels.

The questionnaire also collected information regarding the patient's most recent fasting blood-glucose (FBG), lipid levels, blood pressure, and any diabetes-related complications, such as dyslipidemia, hypertension, macrovascular diseases, eye disorders, kidney disorders, erectile dysfunction, and/or diabetic neuropathy. Diabetes medications, insulin, and macrovascular medications were also recorded. Information was collected on any specialists the patient had consulted, any challenges related to T2DM management, and plans for future T2DM management. In addition, the demographic questions included information regarding the patient's lifestyle. To maximize validity, instructions on how to complete the questionnaire were provided.

Descriptive statistical analyses were performed on all variables. Multivariate logistic regression analyses were performed to test the possibility of association between the outcome measures and duration of the disease. The independent variables were age, gender, body mass index (BMI), current prescription(s), prescription medication insurance coverage, glycemic management, lifestyle, number of comorbidities, and compliance with recommendations/therapy. All statistical analyses were conducted using SAS software (SAS software version 6.12, SAS Institute Inc., Cary, NC, USA). A $P$ value of $<0.05$ was considered statistically significant. 


\section{RESULTS}

A total of 3592 completed questionnaires were returned by 377 GPs within the timeframe allotted by the study. On average, each GP contributed 9.5 questionnaires. Of those, 3451 questionnaires (96\%) were eligible for statistical analysis, as follows: Argentina, 728; Brazil, 885; Chile, 486; Mexico, 716; and a group of Caribbean/ Central America/Andean countries (Costa Rica, Ecuador, Guatemala, Peru, and Venezuela), 636. Figures for the later group of countries are also shown separately, but have been totaled together for data analysis purposes, due to the relatively small individual size of each sample.

\section{Independent variables}

Females comprised $53.6 \%$ of the patients. The mean age at diagnosis was 52.4 years, with a standard deviation (SD) of 10.9 years. In just over half $(52.4 \%)$, disease duration was stated as $<5$ years. A family history of T2DM was reported in $60.3 \%$ of the patients. The vast majority $(79.4 \%)$ were overweight, with almost half $(38.3 \%)$ of the patients classified as obese. This was not surprising, as $57.6 \%$ were described as following a poor diet, and $71.5 \%$ as living a sedentary lifestyle. Smoking was relatively uncommon, with only $12.9 \%$ reporting to be smokers. About half of the patients (51.1\%) did not have drug insurance coverage (Table 1).

\section{Comorbid conditions}

Comorbid conditions associated with T2DM were very common in the study population $(86.2 \%)$; only $13.8 \%$ of patients did not have a comorbid condition. The incidence of comorbid conditions increased significantly as disease duration increased. Three or more conditions were reported to be present in $58.8 \%$ of patients with T2DM duration $\geq 15$ years, with hypertension and dyslipidemia being the most common. While the prevalence

TABLE 1. Diabetes patient demographics in nine countries of Latin America, 2005

\begin{tabular}{lc}
\hline \multicolumn{1}{c}{ Demographic } & Responses \\
\hline Gender $(n=3$ 441) male/female & $46.4 \% / 53.6 \%$ \\
Current age (years) $(n=3451)$ mean \pm SD $^{\mathrm{a}}$ & $59.7 \pm 10.5$ \\
Age at diagnosis (years) $(n=3$ 394) mean $\pm \mathrm{SD}$ & $52.4 \pm 10.9$ \\
Duration of T2DM ${ }^{\mathrm{b}}$ (years) $(n=3$ 394) & \\
Mean \pm SD & $7.3 \pm 7.1$ \\
$\leq 2$ & $28.9 \%$ \\
$3-5$ years & $23.5 \%$ \\
$6-9$ years & $18.2 \%$ \\
$10-14$ years & $15.7 \%$ \\
$\geq 15$ years & $13.7 \%$ \\
Current BMlc $\left(\mathrm{kg} / \mathrm{m}^{2}\right)(n=3$ 380) & \\
Mean \pm SD & $29.3 \pm 5.3$ \\
$<18.5$ & $0.4 \%$ \\
$18.5-24.9$ & $20.2 \%$ \\
$25.0-29.9$ & $41.1 \%$ \\
$\geq 30$ & $38.3 \%$ \\
Lifestyle factors $(n=3$ 451) & \\
Smoking & $12.9 \%$ \\
Follows a poor diet & $57.6 \%$ \\
Lives a sedentary life/does little exercise & $71.5 \%$ \\
Family history of T2DM & $60.3 \%$ \\
Current prescription drug insurance coverage $(n=3216)$ & \\
Third party payer only & $23.8 \%$ \\
Public payer only & $24.1 \%$ \\
Both & $1.0 \%$ \\
None & $51.1 \%$ \\
\hline
\end{tabular}

a $\mathrm{SD}=$ standard deviation

${ }^{\mathrm{b}} \mathrm{T} 2 \mathrm{DM}=$ type 2 diabetes mellitus.

${ }^{\mathrm{c}} \mathrm{BMI}=$ body mass index.

of dyslipidemia was not affected by the duration of T2DM, hypertension increased with disease duration. Other reported comorbidities also frequently increased with T2DM duration. The incidence of microvascular-related diseases, such as diabetic retinopathy, nephropathy, and neuropathy, showed a significant increase with duration of T2DM (Table 2) as well.

\section{Diabetes control}

The mean FBG +/- SD at initial T2DM diagnosis was $214+/-92$ $\mathrm{mg} / \mathrm{dL}$. At the time of the survey, it was lower: $149.6+/-57.7 \mathrm{mg} / \mathrm{dL}$. The most recent FBG levels were $\geq 110$ $\mathrm{mg} / \mathrm{dL}$ in $78 \%$ of patients, indicating an inadequate level of glycemic control (Table 3). Most GPs (70.5\%) verified their patients' glycemic control using an $\mathrm{HbA1c}$ test. The number of patients for whom the most recent $\mathrm{HbA} 1 \mathrm{c}$ test result was $<7.0 \%$ was $43.2 \%$, while a result of $<6.5 \%$ was seen in $30.0 \%$. For 1271 patients, it was possible to compare the $\mathrm{HbA} 1 \mathrm{c}$ at the time of diagnosis with that of the survey time. Of these patients, $50.5 \%$ showed a reduction of $\geq 0.7 \%$ in HbA1c (Table 3). Glycemic control decreased significantly with increased T2DM duration (HbA1c: $P<$ 0.001 and FBG: $P<0.001$ ) (Figure 1). The mean $\mathrm{HbA1c}$ level for each participating country is presented in Figure 2.

\section{Diabetes treatment}

The most frequently used oral hypoglycemics were biguanides (51\%) and sulphonylureas (36\%). These were combined with other therapies in many cases: sulphonylurea with biguanide in 19\%; and either sulphonylurea or biguanide with a glitazone in $14 \%$, 
TABLE 2. Comorbidities by duration of type 2 diabetes mellitus (T2DM) in nine countries of Latin America, 2005

\begin{tabular}{|c|c|c|c|c|c|c|}
\hline \multirow[b]{2}{*}{ Comorbidity } & \multicolumn{6}{|c|}{ Duration of T2DM (years) } \\
\hline & $\begin{array}{c}\leq 2 \\
n=980\end{array}$ & $\begin{array}{c}3-5 \\
n=798\end{array}$ & $\begin{array}{c}6-9 \\
n=619\end{array}$ & $\begin{array}{c}10-14 \\
n=533\end{array}$ & $\begin{array}{c}\geq 15 \\
n=464\end{array}$ & $\begin{array}{c}\text { Total } \\
n=3451\end{array}$ \\
\hline \multicolumn{7}{|l|}{ Comorbidity } \\
\hline None & $21.6 \%$ & $14.7 \%$ & $12.0 \%$ & $7.1 \%$ & $6.0 \%$ & $13.8 \%$ \\
\hline 1 condition & $28.8 \%$ & $25.2 \%$ & $18.6 \%$ & $18.6 \%$ & $17.9 \%$ & $22.9 \%$ \\
\hline 2 conditions & $26.5 \%$ & $27.2 \%$ & $24.2 \%$ & $23.8 \%$ & $17.2 \%$ & $24.5 \%$ \\
\hline 3 or more conditions & $23.1 \%$ & $33.0 \%$ & $45.2 \%$ & $50.5 \%$ & $58.8 \%$ & $38.8 \%$ \\
\hline Prior amputation & $0.0 \%$ & $0.5 \%$ & $0.6 \%$ & $1.9 \%$ & $2.4 \%$ & $0.9 \%$ \\
\hline Congestive heart failure & $1.8 \%$ & $4.0 \%$ & $3.7 \%$ & $5.3 \%$ & $6.0 \%$ & $3.9 \%$ \\
\hline Dyslipidemia & $52.2 \%$ & $57.6 \%$ & $58.3 \%$ & $60.4 \%$ & $55.6 \%$ & $56.5 \%$ \\
\hline Hypertension & $51.9 \%$ & $61.4 \%$ & $64.1 \%$ & $68.3 \%$ & $68.5 \%$ & $61.4 \%$ \\
\hline Left ventricle hypertrophy & $8.1 \%$ & $12.2 \%$ & $12.3 \%$ & $17.1 \%$ & $18.3 \%$ & $12.7 \%$ \\
\hline Prior myocardial infarction & $2.8 \%$ & $4.6 \%$ & $7.1 \%$ & $7.5 \%$ & $8.8 \%$ & $5.7 \%$ \\
\hline Stable angina & $3.1 \%$ & $4.1 \%$ & $5.3 \%$ & $5.6 \%$ & $6.9 \%$ & $4.7 \%$ \\
\hline Prior stroke & $1.7 \%$ & $1.9 \%$ & $1.6 \%$ & $3.2 \%$ & $5.4 \%$ & $2.5 \%$ \\
\hline Symptomatic PVDa & $5.5 \%$ & $4.9 \%$ & $6.8 \%$ & $9.2 \%$ & $13.4 \%$ & $7.4 \%$ \\
\hline Cataracts & $3.4 \%$ & $3.5 \%$ & $7.1 \%$ & $9.8 \%$ & $15.5 \%$ & $6.8 \%$ \\
\hline Diabetic retinopathy & $2.9 \%$ & $6.3 \%$ & $10.0 \%$ & $17.8 \%$ & $25.9 \%$ & $10.4 \%$ \\
\hline Glaucoma & $1.5 \%$ & $1.9 \%$ & $2.4 \%$ & $2.4 \%$ & $4.5 \%$ & $2.3 \%$ \\
\hline Microalbuminuria & $4.4 \%$ & $8.0 \%$ & $12.4 \%$ & $16.3 \%$ & $22.6 \%$ & $11.1 \%$ \\
\hline Nephropathy & $2.4 \%$ & $4.5 \%$ & $8.4 \%$ & $9.6 \%$ & $14.2 \%$ & $6.8 \%$ \\
\hline Diabetic foot disease & $0.7 \%$ & $1.1 \%$ & $2.6 \%$ & $3.9 \%$ & $6.5 \%$ & $2.4 \%$ \\
\hline Depression & $13.1 \%$ & $17.8 \%$ & $19.7 \%$ & $18.9 \%$ & $19.2 \%$ & $17.3 \%$ \\
\hline Erectile dysfunction & $5.1 \%$ & $7.3 \%$ & $15.0 \%$ & $14.8 \%$ & $15.7 \%$ & $10.4 \%$ \\
\hline Neuropathy & $7.7 \%$ & $11.5 \%$ & $17.9 \%$ & $22.5 \%$ & $29.1 \%$ & $15.5 \%$ \\
\hline Macrovascular disease $\mathrm{a}^{\mathrm{a}}$ & $17.8 \%$ & $21.8 \%$ & $27.0 \%$ & $33.2 \%$ & $37.3 \%$ & $25.8 \%$ \\
\hline Microvascular disease ${ }^{b}$ & $15.9 \%$ & $23.9 \%$ & $37.6 \%$ & $46.9 \%$ & $55.4 \%$ & $31.9 \%$ \\
\hline
\end{tabular}

TABLE 3. Glycemic control in nine countries of Latin America, 2005

\begin{tabular}{lcc}
\hline & At diagnosis & Most recent test \\
\hline Fasting blood glucose $(\mathrm{mg} / \mathrm{dL}), n$ & 2683 & 3391 \\
Mean $\pm \mathrm{SD}$ a & $214.3 \pm 92.0$ & $149.6 \pm 57.7$ \\
$<110 \mathrm{mg} / \mathrm{dL}$ & $2.9 \%$ & 22.0 \\
$\geq 110 \mathrm{mg} / \mathrm{dL}$ & $97.1 \%$ & 78.0 \\
$\mathrm{HbA1c}(\%), n$ & 1293 & 3229 \\
Mean $\pm \mathrm{SD}$ & $8.6 \pm 2.3$ & $7.6 \pm 1.9$ \\
$<7.0$ & $22.4 \%$ & $43.2 \%$ \\
$7.0-8.4$ & $31.1 \%$ & $29.7 \%$ \\
$>8.4$ & $46.6 \%$ & $27.0 \%$ \\
Change of $\mathrm{HbA}$ (c from diagnosis $(\%)(n=1271)$ & & \\
Mean $\pm \mathrm{SD}$ & $1.2 \pm 2.1$ & \\
Reduction $\geq 0.7 \%$ & $50.5 \%$ & \\
Reduction $0.1-0.6$ & $12.2 \%$ & \\
No reduction $0 \%$ & $22.4 \%$ & \\
Increase & $14.9 \%$ & \\
\hline
\end{tabular}

$\mathrm{SD}=$ standard deviation

${ }^{b} \mathrm{HbA} 1 \mathrm{C}=$ glycosylated hemoglobin.

with an alfa-glucosidase inhibitor in $2 \%$, or with "other" oral, diabetes medications (repaglinide and/or nateglinide) in $3 \%$.
Insulin was used exclusively, or in combination with an oral agent, by $14.5 \%$ of patients. Glycemic management strategies changed significantly with increased duration of T2DM. In those who reported duration of $\leq 2$ years, only $4 \%$ reported insulin use with or without an oral diabetes med- 

FIGURE 1. Most recent $\mathrm{HbA1c^{a }}$ level category by duration of type 2 diabetes mellitus (T2DM)
in nine countries of Latin America

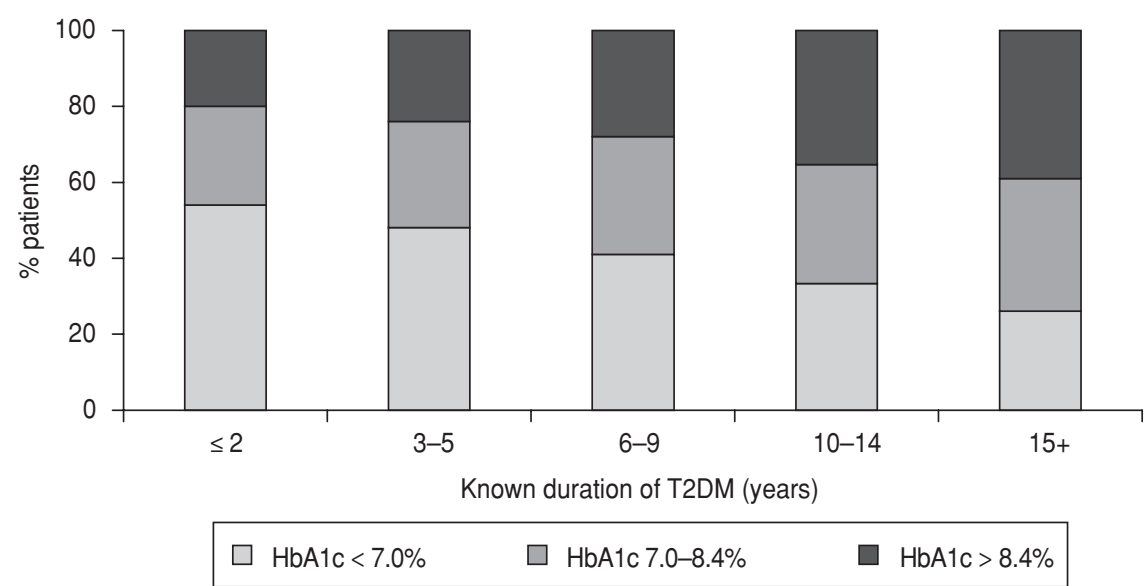

${ }^{a} \mathrm{HbA} 1 \mathrm{C}=$ glycosylated hemoglobin. $\mathrm{HbA} 1 \mathrm{c}$ level increased significantly with the duration of T2DM $(P<0.001)$. Covariates in cluded: age, body mass index category, drug insurance coverage, glycemic management, lifestyle, and global compliance with recommendations/therapy.

FIGURE 2. $\mathrm{HbA1c}^{\mathrm{a}}$ control in nine countries of Latin America, 2005

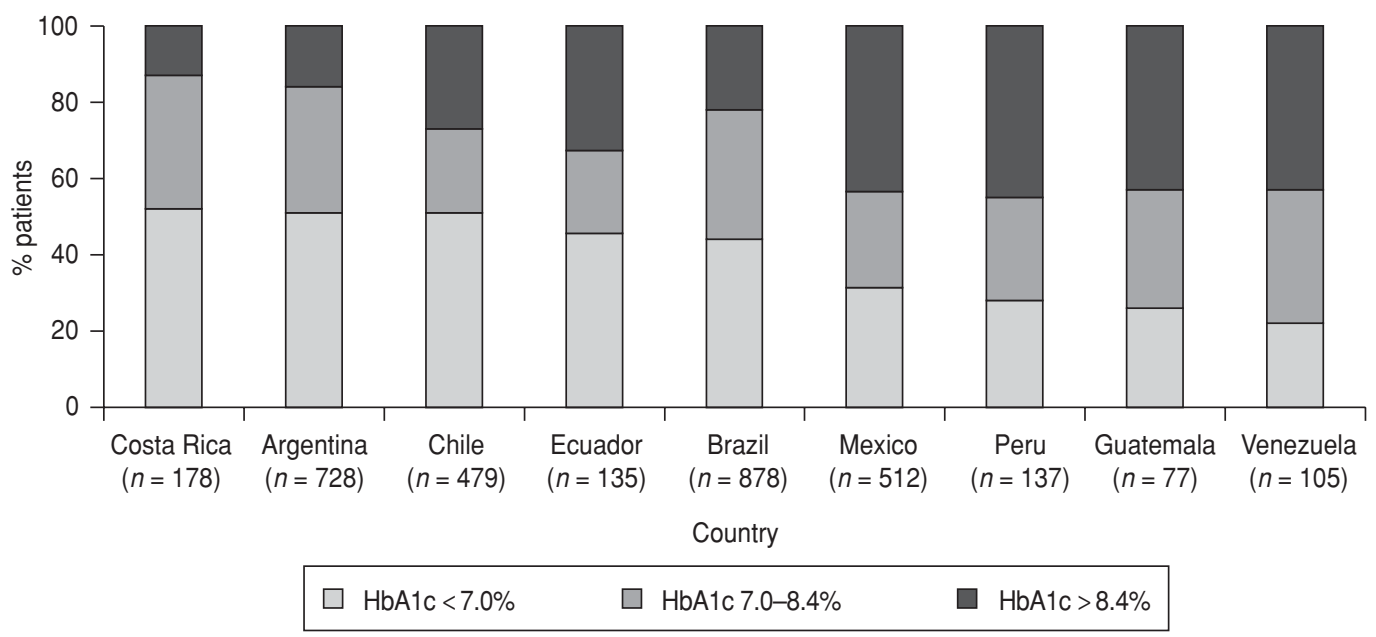

${ }^{a} \mathrm{HbA1C}=$ glycosylated hemoglobin.

ication; however, in those reporting duration $\geq 15$ years, 37\% were using insulin (Figure 3).

\section{Specialist visits}

Most patients (75.7\%) had visited one or more specialists, at some point, since their T2DM diagnosis; $65.5 \%$ had visited one or more specialists during the preceding year (Table 4). Cardiologists and ophthalmologists were the most frequently consulted specialists, followed by internists and endocrinologists. Most patients $(80.6 \%)$ had never had a consultation with a diabetes educator.

\section{Control strategies/challenges}

When GPs were asked to identify the challenges of treating patients with $\mathrm{HbA} 1 \mathrm{c} \geq 7 \%$, ensuring compliance with diet and exercise were the most frequently reported problems (Table 5). When asked about improving the patients' glycemic control, compliance 
FIGURE 3. Drug usage over time in nine countries of Latin America, 2005

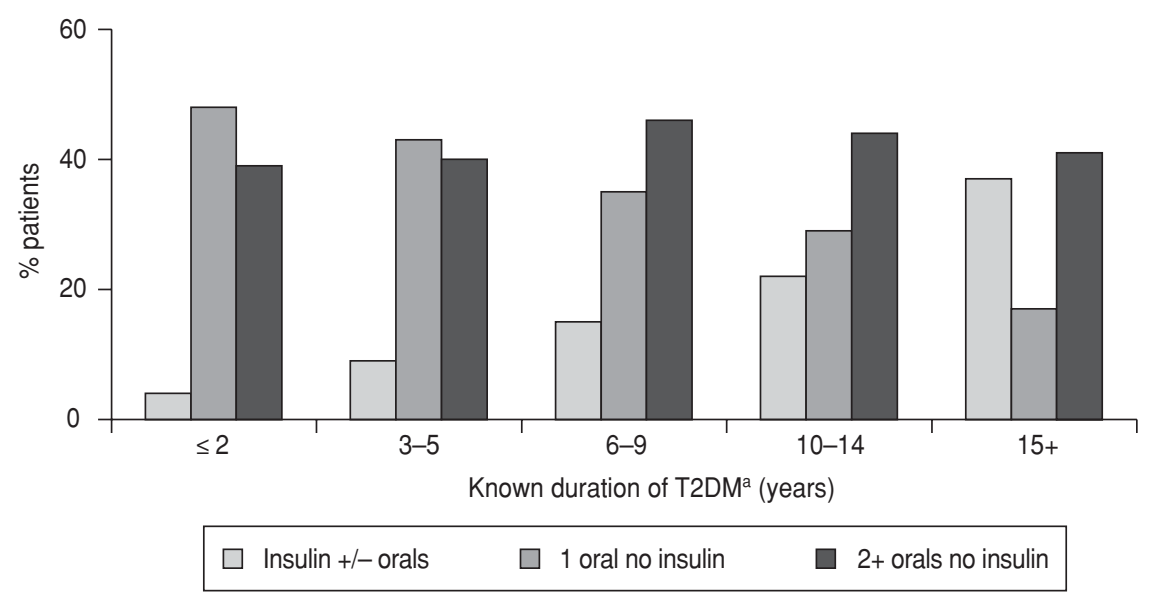

a T2DM = type 2 diabetes mellitus.

TABLE 4. Patient contact with specialist in nine countries of Latin America, 2005

\begin{tabular}{lcc}
\hline \multicolumn{1}{c}{ Specialist } & $\begin{array}{c}\text { Ever visited } \\
(n=3451)\end{array}$ & $\begin{array}{c}\text { Visited in past year } \\
(n=3451)\end{array}$ \\
\hline Patient contact with specialist & & \\
$\quad$ None & $24.3 \%$ & $34.5 \%$ \\
$\quad$ specialist & $21.6 \%$ & $23.6 \%$ \\
2 specialists & $21.5 \%$ & $18.8 \%$ \\
3 or more specialists & $32.6 \%$ & $23.1 \%$ \\
& & \\
Endocrinologist & $30.1 \%$ & $18.4 \%$ \\
Internal medicine specialist & $38.1 \%$ & $29.1 \%$ \\
Cardiologist & $40.8 \%$ & $34.1 \%$ \\
Nephrologist & $7.2 \%$ & $5.2 \%$ \\
Ophthalmologist & $44.9 \%$ & $38.1 \%$ \\
Optometrist & $4.7 \%$ & $4.1 \%$ \\
Chiropodist/Podiatrist & $3.5 \%$ & $3.3 \%$ \\
Diabetes educator & $19.4 \%$ & $12.9 \%$ \\
\hline
\end{tabular}

with medication and with glucose selfmonitoring were cited as challenges by around $30 \%$ of GPs. Drug coverage (either by the public health care system or private insurance) and polypharmacy were considered challenges by a minority of GPs.

When asked how they planned to help their patients achieve better glycemic control, $80.7 \%$ of GPs indicated that they would reinforce the importance of a healthy lifestyle, and $59.5 \%$ cited aggressive medical management in patients with $\mathrm{HbA} 1 \mathrm{c} \geq 7 \%$. Prescribing insulin, increasing the dose of insulin, and referral to a specialist were less frequently cited among planned activities for improved glycemic control (Table 6).

\section{DISCUSSION}

T2DM is a major health problem in Latin America (14) and is edging its way toward becoming a major epidemic with high costs that will tax health care systems (both at private, as well as public levels), some of which already run at a deficit. The prevalence of diabetes in Latin America is forecast to double over the next two decades, resulting in a major economic burden (4). While the disease's primary treatment represents a considerable cost, it is the long-term conditions and complications resulting from poor management that will be the bulk of the economic burden (4). Moreover, the direct costs of treating complications will be compounded by the indirect costs-loss of productivity, absenteeism, and disability.

The DEAL study was designed to understand T2DM patient management in Latin America and measure how successful treatment and control, as prescribed by GPs in private practice, are in preventing associated complications. When designing the DEAL study, the team sought a population of patients similar to that of other sur- 
TABLE 5. Challenges to improve $\mathrm{HbA} 1 \mathrm{c}^{\mathrm{a}}$ for patients with $\mathrm{HbA1c} \geq 7 \%$ in nine countries of Latin America, 2005

\begin{tabular}{lr}
\hline \multicolumn{1}{c}{ Challenges } & $\begin{array}{r}\text { Patients with } \\
\text { HbA1c } \geq 7 \% \\
(n=1833)\end{array}$ \\
\hline No challenges & $7.3 \%$ \\
Drug coverage & $12.5 \%$ \\
Lack of interest/concern & $31.0 \%$ \\
Comorbid conditions & $19.5 \%$ \\
Cultural & $26.8 \%$ \\
Knowledge & $18.2 \%$ \\
Compliance with diet & $78.3 \%$ \\
Compliance with exercise & $75.6 \%$ \\
Compliance with medication & $30.9 \%$ \\
Compliance with self-glucose & \\
$\quad$ monitoring & $30.8 \%$ \\
Polypharmacy/multiple medications & $12.1 \%$ \\
Other & $3.3 \%$ \\
\hline
\end{tabular}

${ }^{\mathrm{a}} \mathrm{HbA} 1 \mathrm{c}=$ glycosylated hemoglobin.

veys of diabetic patients, both in Latin America (9) and in other areas of the world $(15,16)$, with a population that would represent the diabetic population of Latin America as a whole. However, since public physicians were not included-both for logistical reasons and because of difficulties regarding patient follow-up-a potential bias may exist. DEAL may have selected higher-income, better-educated patients who have access to higher standards of care and to better medications. Accordingly, the study's results, although significant and representative, are not expected to be applied across the board in Latin America.

The DEAL results showed that in Latin America, T2DM control in the private sector is poor; therefore, it can be expected to be worse in the public health sector, where, in general, there are fewer care and medication options. Also noteworthy is that in Latin America, most private health insurance plans cover medical assistance, medical procedures, and hospitalization, but do not cover prescription medications; as a result, at least $50 \%$ of patients, in general, do not have drug insurance/reimbursement, regardless of the disease.

Based on measurements of FBG and $\mathrm{HbA1c}$ levels, the results of the survey
TABLE 6. Plans to achieve $\mathrm{HbA1c^{a }}$ target for patients with $\mathrm{HbA1C} \geq 7 \%$ in nine countries of Latin America, 2005

\begin{tabular}{|c|c|}
\hline Plans & $\begin{array}{c}\text { Patients with } \\
\mathrm{HbA} 1 \mathrm{c} \geq 7 \% \\
(n=1833)\end{array}$ \\
\hline No action & $2.9 \%$ \\
\hline Reinforce lifestyle & $80.7 \%$ \\
\hline Increase dose OHA & $30.3 \%$ \\
\hline Add $\mathrm{OHA}$ & $20.5 \%$ \\
\hline Add insulin & $9.4 \%$ \\
\hline Increase dose insulin & $11.3 \%$ \\
\hline Refer to specialist & $9.6 \%$ \\
\hline Aggressive medication management & $59.5 \%$ \\
\hline
\end{tabular}

suggest that patients' blood glucose is not well controlled, and that, as disease duration increases, control diminishes further. It was not surprising then, that given the results on glycemic control, more than $50 \%$ of patients with disease duration $\geq 6$ years had three or more comorbid conditions. As other studies have shown, microvascular diseases increased with disease duration (17-19). For example, the presence of diabetic retinopathy for the group, as a whole, was $10.4 \%$, but increased progressively from $2.9 \%$, where disease duration was $\leq 2$ years, to $25.9 \%$ where it was $\geq 15$ years.

Interestingly, the same was not observed in macrovascular disease prevalence. This finding can be explained by the fact that macrovascular disease pathogenesis in T2DM starts before the appearance of hyperglycemia (20-22). As expected, most patients were classified as either overweight or obese, and the vast majority had a family history of the disease, as well as a poor diet and a sedentary lifestyle.

Most patients were reported to have consulted specialists. The specialists consulted were mainly those treating the primary disease (endocrinologists and internists) or comorbid conditions (cardiologists and ophthalmologists).

Patient education appeared to be largely ignored, with fewer than $20 \%$ of the patients ever having been seen by a diabetes educator. A similar lack of disease management education has been observed in other studies in Latin American countries (6).

The glycemic control strategy most widely cited by the GPs was a "healthy lifestyle," despite the challenge that these same GPs said they face when seeking to alter a patient's perception of their need for a healthy diet and exercise. Not only are a healthy diet and physical activity pivotal to diabetes care, they can help prevent diabetes and other chronic conditions, such as hypertension and hyperlipidemia. While the benefits of healthy eating and exercise have long been recognized, their absence from the average lifestyle in developed countries is a major problem. Lifestyle changes are cheaper, less invasive ways to prevent and treat diabetes. GPs, government health care systems, and private health care systems would all benefit from working together in a healthy lifestyles campaign.

Nevertheless, the importance of early, aggressive intervention with medication that addresses the dual pathophysiology of T2DM (i.e., insulin resistance and/or insulin deficiency), should be reiterated, and this option pursued immediately if lifestyle intervention is failing. In addition, the role that undertreatment plays in developing countries-due to either medical noncompliance with current guidelines or patient noncompliance to prescribed medication-should not be underestimated.

Accordingly, the second mostwidely cited strategy for improving glucose control was aggressive medication management, specifically, the following four options: (1) increasing the dose of the currently prescribed oral hypoglycemic agent, (2) supplementing treatment with an additional oral hypoglycemic, (3) introducing insulin therapy, and/or (4) increasing the current insulin dose. Combination therapy has been shown to improve glucose control where monotherapy has proved inadequate (23).

In general, the GPs' responses show appropriate knowledge of diabetes care and control options-most impor- 
tantly, lifestyle changes and aggressive medication therapy-but difficulties when applying this knowledge. Patient noncompliance could be due to the lack of a proper diabetes education program, a shortcoming that may be more prevalent in private practice. Noncompliance may also be due to economic and/or cultural factors.

Overall, the DEAL study has shown that (1) T2DM treatment has several similarities across countries and practitioners in Latin America, (2) diabetes control is poor, particularly in some specific countries, (3) among the study population, blood glucose control deteriorates with increased disease duration, and (4) deteriorating T2DM control gives way to a concomitant rise in comorbidities.
According to the GPs surveyed, the current management approaches appear to be insufficient in altering the course of the disease. There is ample evidence that good medical management, particularly tight glucose control, is associated with fewer long-term complications (23). Accurate and continuous glucose control has been particularly associated with the development of fewer microvascular complications (17). There is also evidence to suggest that glucose control is associated with the development of fewer macrovascular complications (18), although good blood pressure and lipid management are also essential to reducing the incidence of these events (19).

Studies have indicated that in patients with T2DM, the increased treat- ment costs associated with intensive, blood-glucose control are more than compensated by the increased time free of complications and the reduced cost of complications (24). The results of the DEAL study, coupled with these others, suggest that a more efficient diabetes control program for patients in Latin America is not only justified, but imperative.

Acknowledgements. The DEAL study was funded by GlaxoSmithKline. Special thanks go to the general practitioners and patients who made this study possible; to Maristela Precivale, biostatistician from Intrials, for the statistical analysis; and to Dr. Sharon McCullough, for expert assistance in preparing the manuscript.

\section{REFERENCES}

1. Wild S, Roglic G, Green A, Sicree R, King H. Global prevalence of diabetes: estimates for the year 2000 and projections for 2030. Diabetes Care. 2004;27(5): 1047-53.

2. Hennis A, Wu SY, Nemesure B, Li X, Leske MC, Barbados Eye Study Group. Diabetes in a Caribbean population: epidemiological profile and implications. Int J Epidemiol. 2002; 31(1):234-9.

3. Carulli L, Rondinella S, Lombardini S, Canedi I, Loria P, Carulli N. Review article: diabetes, genetics and ethnicity. Aliment Pharmacol Ther. 2005;22 (Suppl 2):16-9.

4. Aschner P. Diabetes trends in Latin America. Diabetes Metab Res Rev. 2002;18(Suppl 3): S27-31.

5. Wilks R, Rotimi C, Bennett F, McFarlaneAnderson N, Kaufman JS, Anderson SG et al. Diabetes in the Caribbean: results of a population survey from Spanish Town, Jamaica. Diabet Med. 1999;16(10):875-83.

6. Assuncao MC, Santos Id, Gigante DP. Atenção primária em diabetes no Sul do Brasil: estrutura, processo e resultado. Rev Saude Publica. 2001;35(1):88-95.

7. Baechler R, Mujica V, Aqueveque X, Ramos L, Soto A. Prevalencia de diabetes mellitus en la VII Región de Chile. Rev Med Chil. 2002;130 (11): 1257-64.

8. Wilks RJ, Sargeant LA, Gulliford MC, Reid ME, Forrester TE. Management of diabetes mellitus in three settings in Jamaica. Rev Panam Salud Publica. 2001;9(2):65-72.

9. Aguilar-Salinas CA, Velazquez Monroy O, Gomez-Perez FJ, Gonzalez Chavez A, Esqueda AL, Molina Cuevas V, et al. Characteristics of patients with type 2 diabetes in Mexico: results from a large population-based nationwide survey. Diabetes Care. 2003;26(7): 2021-6.
10. Barceló A, Aedo C, Rajpathak S, Robles S. The cost of diabetes in Latin America and the Caribbean. Bull World Health Organ. 2003; 81(1):19-27.

11. Gagliardino JJ, de la Hera M, Siri F, Grupo de Investigación de la Red QUALIDIAB. Evaluación de la calidad de la asistencia al paciente diabético en América Latina. Rev Panam Salud Publica. 2001;10(5):309-17.

12. American Diabetes Association. Standards of medical care for patients with diabetes mellitus. Diabetes Care. 2003;26(Suppl 1):S33-50.

13. Burlando G, Sánchez RA, Ramos FH, Mogensen $C E$, Zanchetti $A$ and On behalf of the Latin American Experts Group. Latin American consensus on diabetes mellitus and hypertension. J Hypertens. 2004; 22: 2229-41.

14. Barceló A, Rajpathak S. Incidence and prevalence of diabetes mellitus in the Americas. Rev Panam Salud Publica. 2001;10(5):300-8.

15. Nelson KM, Reiber G, Boyko EJ, NHANES III. Diet and exercise among adults with type 2 diabetes: findings from the third national health and nutrition examination survey (NHANES III). Diabetes Care. 2002;25(10): 1722-8.

16. Harris SB, Ekoe JM, Zdanowicz Y, WebsterBogaert S. Glycemic control and morbidity in the Canadian primary care setting (results of the diabetes in Canada evaluation study). Diabetes Res Clin Pract. 2005;70(1):90-7.

17. Kerner W. The UK prospective diabetes study [letter]. Lancet. 1998;352(9144):1934.

18. Selvin E, Marinopoulos S, Berkenblit G, Rami T, Brancati FL, Powe N.R., et al. Meta-analysis: glycosylated hemoglobin and cardiovascular disease in diabetes mellitus. Ann Intern Med. 2004;141(6):421-31.

19. Stratton IM, Adler AI, Neil HA, Matthews DR, Manley SE, Cull CA, et al. Association of glycaemia with macrovascular and microvascular complications of type 2 diabetes (UKPDS 35): prospective observational study. BMJ. 2000;321(7258):405-12.

20. Hu FB, Stampfer MJ, Haffner SM, Solomon CG, Willett WC, Manson JE. Elevated risk of cardiovascular disease prior to clinical diagnosis of type 2 diabetes. Diabetes Care. 2002; 25:1129-34.

21. Hunt KJ, Williams K, Rivera D, O'Leary DH, Haffner SM, Stern MP, Gonzales Villalpando C. Elevated carotid artery intima-media thickness levels in individuals who subsequently develop type 2 diabetes. Arterioscler Thromb Vasc Biol. 2003;23:1845-50.

22. Khaw K-T, Wareham N, Bingham S, Luben R, Welch A, Day N. Association of hemoglobin A1c with cardiovascular disease and mortality in adults: the European prospective investigation into cancer in Norfolk. Ann Intern Med. 2004;141:413-20.

23. Chacra AR, Davidson JA, Diaz J, EscalantePulido M, Litwak LE, Mestman JH, et al. An algorithm for the treatment of type 2 diabetes in Latin America. Diabetes Obes Metab. 2005; 7(2):148-60.

24. Gray A, Raikou M, McGuire A, Fenn P, Stevens R, Cull C, et al. Cost effectiveness of an intensive blood glucose control policy in patients with type 2 diabetes: economic analysis alongside randomised controlled trial (UKPDS 41). United Kingdom Prospective Diabetes Study Group. BMJ. 2000;320(7246): 1373-8.

Manuscript received 17 July 2006. Revised version accepted for publication 26 May 2007. 
RESUMEN Objetivos. Comprender mejor cómo los médicos generales/no especialistas del sector privado atienden y controlan la diabetes en nueve países de América Latina e identificar los principales problemas relacionados con el paciente y el médico, que obstaculizan la atención.

\section{Control de la diabetes mellitus tipo 2 por médicos generales del sector privado en nueve países de América Latina}

Palabras clave
Métodos. Se realizó un estudio epidemiológico, multicéntrico, transversal, en nueve países de América Latina: Argentina, Brasil, Chile, Costa Rica, Ecuador, Guatemala, México, Perú y Venezuela. Se pidió a los médicos generales del sector privado la información sobre la atención y el control de sus pacientes de 18 a 75 años de edad con diabetes mellitus tipo 2 (DMT2), así como los datos demográficos, la historia clínica y de medicación, las pruebas de laboratorio e información sobre los retos relacionados con la atención del paciente.

Resultados. De los 3592 cuestionarios de pacientes entregados por 377 médicos, $60 \%$ de los pacientes tenían antecedentes familiares de diabetes, 58\% seguían una dieta inadecuada, $71 \%$ eran sedentarios y $79 \%$ presentaban obesidad o sobrepeso. Se observó un inadecuado control glucémico (glucemia en ayunas $\geq 110 \mathrm{mg} / \mathrm{dL}$ ) en $78 \%$ de los pacientes. La proporción de pacientes con $\mathrm{HbA} 1 \mathrm{c}<7,0 \%$ fue de $43,2 \%$. El control glucémico se redujo significativamente al aumentar la duración de la DMT2. En $86 \%$ de los pacientes se encontraron enfermedades concurrentes asociadas con la DMT2; el uso de insulina y las enfermedades concurrentes - especialmente las asociadas con complicaciones microvasculares - incrementaron significativamente la duración de la diabetes. En cuanto al tratamiento de los pacientes, el reto más frecuentemente citado fue garantizar la adhesión a la dieta y al plan de ejercicios recomendados.

Conclusiones. Los niveles de glucemia no están suficientemente controlados en los pacientes con DMT2 que se atienden en el sistema privado de salud de América Latina, particularmente en los pacientes que han tenido la enfermedad por más tiempo (> 15 años). Tomado en cuenta las diferencias entre la atención sanitaria privada y la pública en América Latina, especialmente en lo concerniente a la calidad de la atención y el acceso a los medicamentos, se requieren estudios adicionales en el sector público. En general, se necesita un programa más eficiente e intensivo de control de la DMT2 y programas eficaces de educación de los pacientes, ajustados a las realidades de América Latina.

Diabetes mellitus tipo 2, complicaciones de la diabetes, accesibilidad a los servicios de salud, cooperación del paciente, América Latina.

\begin{tabular}{|l}
\hline \multicolumn{1}{|c|}{ Alimentos, nutrición y la prevención del cáncer: una perspectiva mundial } \\
Este libro se refiere explícitamente a la prevención primaria del cáncer desde una \\
perspectiva mundial. Se subrayan los aspectos de la alimentación y la nutrición que \\
probablemente reduzcan el riesgo de cáncer, y se les da la importancia que merecen a \\
los que podrían incrementar ese riesgo. \\
Este libro sólo se puede adquirir en formato electrónico por medio de Ingenta Select: \\
* Visite el sitio: http://www.ingentaselect.com \\
* Seleccione "Pan American Health Organization" en la opción Browse by publishers \\
* Seleccione cualquiera de los títulos ofrecidos
\end{tabular}

